\title{
Correlation of vitamin D levels with burden of white matter lesions in individuals with Prader-Willi syndrome
}

\author{
Jennifer L Miller ${ }^{1}$, Ilona M Schmalfuss ${ }^{2}$ \\ 1. Department of Pediatrics, University of Florida, Gainesville, USA. 2. Department of Radiology, North Florida/South \\ Georgia Veterans Administration Hospital, University of Florida, Gainesville, USA.
}

Correspondence: Jennifer L Miller. Address: Department of Pediatrics, Division of Endocrinology, University of Florida, Gainesville, USA. Email: millejl@peds.ufl.edu

Received: September 18, 2014 Accepted: November 10, 2014 Online Published: December 10, 2014

DOI : $10.5430 /$ ijdi.v2n1p47

URL: http://dx.doi.org/10.5430/ijdi.v2n1p47

\begin{abstract}
Objective: Vitamin D has a variety of roles, including bone metabolism, calcium homeostasis, immunomodulation, anti-inflammation, and possibly neuroprotection. Neuroimaging has shown that hypovitaminosis D may cause more rapid progression and increased severity of white matter hyperintensities (WMH) in some populations. Individuals with Prader-WIlli syndrome (PWS) often have inadequate vitamin D intake, so we investigated if the burden of WMH in PWS is associated with hypovitaminosis $\mathrm{D}$.

Design/Methods: We evaluated brain MRI's of 20 individuals with vitamin D levels measured at the time of the scan, who were between ages 5 and 46 years and had PWS $(n=17)$ or were typical siblings $(n=3)$. The presence and number of WMH were correlated with vitamin D.

Results: Serum vitamin D levels were inversely correlated with the presence and number of WMH (0.025) in individuals with PWS and controls, as well as the progression of WMH $(p=0.029)$ in PWS. Additionally, vitamin D levels correlated with cognitive scores in PWS $(p<0.01)$.

Conclusions: The results of this small study support that vitamin D has neuroprotective effects influencing the development and progression of WMH even in the pediatric population. Studies should be done in children with high prevalence of vitamin D deficiency such as obesity.
\end{abstract}

\section{Keywords}

Prader-Willi syndrome, Vitamin D

\section{I ntroduction}

Prader-Willi syndrome (PWS) is a complex genetic disorder which is caused by the absence of normally active paternally expressed genes from the chromosome 15q11-q13 region. Features of PWS include poor feeding in infancy that is often associated with failure to thrive and obesity beginning around 2 years of age. In addition, patients demonstrate hyperphagia, hypotonia, developmental and cognitive delays, behavioral problems, sleep abnormalities, and neuroendocrine aberrations ${ }^{[1,2]}$. Hyperphagia is extremely common as children with PWS get older. It leads to worsening of the 
obesity, and increased risk of metabolic and cardiovascular complications. Individuals with PWS also have a lower resting energy expenditure and lower muscle mass compared to body mass index (BMI)-matched controls, which further increases their risk for severe obesity. In order to ameliorate the obesity, most physicians and dieticians recommend a strict, low-fat, low-calorie diet ${ }^{[3]}$.

Because of the need for reduced caloric diet to help lessen the obesity, vitamin D intake is inadequate in most children with PWS ${ }^{[4]}$. It has been also shown that plasma 25-hydroxyvitamin D (25OHD) levels are inversely related to BMI with sequestration of vitamin $\mathrm{D}$ in the excess adipose tissue postulated as the underlying mechanism. Therefore, vitamin $\mathrm{D}$ deficiency is common in obesity including individual with PWS ${ }^{[5-7]}$ and their increased risk of developing obesity related complications such as insulin resistance, hypertension, and low- grade inflammation ${ }^{[6,7]}$.

Low levels of 25OHD are known to lead to accelerated bone turnover and increased risk of fractures. More importantly, 25OHD levels have been negatively associated with inflammatory parameters such as C-reactive protein (CRP) and C3 and C4 levels ${ }^{[8,9]}$. Increased CRP levels in turn have been linked to cerebral small-vessel disease10 with brain imaging data showing ischemic infarcts and white matter hyperintensities (WMH) in individuals with low levels of 25OHD ${ }^{\text {[11] }}$. Additionally, deficiency of 25OHD has been associated with dysfunction of the frontal-subcortical neuronal circuits, particularly the dorsolateral circuit, which could play a role in explaining the cognitive dysfunction observed in patients with PWS ${ }^{[11]}$.

Vitamin D deficiency is associated with cognitive and executive function decline in the elderly population ${ }^{\text {[12-14] }}$. Vitamin D insufficiency and deficiency has been also linked to dementia (e.g. Alzheimer disease), stroke, and white matter demyelination reflected as WMH on brain MRI scans ${ }^{[11,15,16]}$.

We have published previously that individuals with PWS and early-onset morbid obesity have WMH on brain MRI and suffer from cognitive dysfunction ${ }^{[17]}$. In this study we sought to prove the hypothesis that WMH and decreased cognitive function in individuals with PWS are associated with vitamin D deficiency.

\section{Methods and procedures}

This study involved a sub-set of individuals who were participating in a clinical research study investigating the prevalence of structural brain abnormalities in individuals with PWS, early-onset obesity, and normal weight sibling controls. The study was approved by the Institutional Review Board at the University of Florida and all guardians provided informed consent. Seventeen individuals with PWS (8 male/9 female; ages 5-46 years) and 3 normal weight control siblings (2 males/1 female; ages 6-12 years) had vitamin D levels measured at the time of their brain MRI scan. All individual also underwent repeated MRI scanning 2 years after the initial brain MRI. MRI scans were performed on a Phillips 3-Tesla scanner. WMH were documented on a fluid attenuation inversion recovery (FLAIR) sequence and counted by a neuroradiologist who was blinded to the diagnosis and age of the subjects (IS). Statistical analysis was done using Spearman correlations between presence and number of WMH and vitamin D levels.

Cognitive and achievement testing was performed on all individuals using the Woodcock-Johnson Test of Cognitive Abilities. Body fat was measured using a DEXA (dual energy x-ray absorptiometry; General Electric) scanner at the University of Florida, and body mass index standard deviation (BMI SDS) was calculated using growth charts from the Centers for Disease Control.

\section{Results}

Thirty-seven individuals with PWS had brain MRI scans, but only 17 had serum vitamin D levels measured at the time of their scan. Thirty controls underwent MRI examinations, with 3 having serum 25OHD levels measured. Therefore, only 
the 20 individuals with both vitamin D levels and brain MRI scans were used for the analysis in this study. Twelve of the 17 individuals with PWS had WMH, ranging from 1 to greater than 50 in number (see Table 1). Two of the controls had WMH, with one having 5 lesions at age 10 and one having $28 \mathrm{WMH}$ at age 12 . Neither of the controls were obese and their mean BMI standard deviation score (SDS) was 0.16, while two of the individuals with PWS and WMH were obese with BMI SDS greater than 2. The mean BMI SDS for the group was 1.26. Within the 20 individuals who had 25OHD levels measured at the time of their scan, the presence and number of WMH did not correlate with BMI SDS, percentage of body fat, age, gender, or general intellectual ability (GIA) (see Table 1).

Table 1. Characteristics of individuals in study

\begin{tabular}{|c|c|c|c|c|c|c|}
\hline Patient \#/ Sex & Diagnosis & Age & BMI SDS & $\begin{array}{l}\text { General } \\
\text { Intellectual } \\
\text { Ability (IQ) }\end{array}$ & 250HD level & \#WMH \\
\hline 1 & PWS & 33 & 1.22 & 74 & 20 & 7 \\
\hline 2 & PWS & 24 & 0.39 & 64 & 22.3 & 15 \\
\hline 3 & PWS & 40 & 1.66 & 80 & 24 & 51 \\
\hline 4 & PWS & 7 & 2.94 & 64 & 27 & 0 \\
\hline 5 & PWS & 5 & 0.68 & 81 & 28 & 5 \\
\hline 6 & PWS & 46 & 1.88 & 78 & 31.7 & 11 \\
\hline 7 & PWS & 18 & 1.45 & 88 & 32.6 & 2 \\
\hline 8 & PWS & 28 & 1.03 & 64 & 33.1 & 0 \\
\hline 9 & PWS & 30 & 0.84 & 74 & 34.7 & 11 \\
\hline 10 & PWS & 19 & 2.27 & 83 & 37 & 0 \\
\hline 11 & PWS & 26 & 1.11 & 65 & 38 & 1 \\
\hline 12 & PWS & 22 & 1.99 & 56 & 38 & 14 \\
\hline 13 & PWS & 7 & -0.60 & 82 & 42.2 & 5 \\
\hline 14 & PWS & 6 & 1.07 & 91 & 44.2 & 0 \\
\hline 15 & PWS & 5 & 1.77 & 56 & 46.8 & 0 \\
\hline 16 & PWS & 31 & 0.8 & 66 & 60 & 0 \\
\hline 17 & PWS & 15 & 1.07 & 62 & 64 & 3 \\
\hline 18 & Control & 6 & 0.50 & 129 & 44.2 & 0 \\
\hline 19 & Control & 10 & 0.35 & 124 & 29.3 & 5 \\
\hline 20 & Control & 12 & -0.36 & 120 & 27.1 & 28 \\
\hline
\end{tabular}

Serum 25OHD levels were inversely correlated with the number and prevalence of WMH $(p=0.025$; see Table 1; Figure 1). Thirteen of the seventeen individuals with PWS had PWS due to deletion. Nine individuals with WMH had deletion-type PWS, while only 1 individual with PWS due to UPD had WMH $(p<0.01)$.

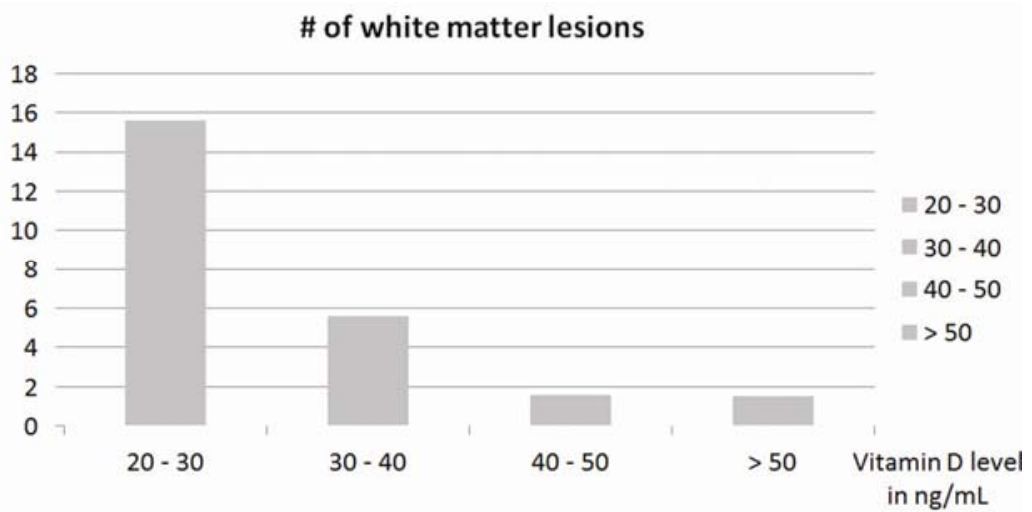

Figure 1. Relationship of vitamin D levels with number of White Matter Hyperintensities 
25OHD levels did correlate with overall GIA $(p<0.001)$ in the individuals with PWS, but not in the sibling controls. However, the number of WMH did not correlate with overall GIA in the population ( $p=0.87)$, suggesting that there may be independent effects of hypovitaminosis D on cognitive skills in these individuals. The level of 25OHD did not correlate with total achievement scores, cognitive speed, or verbal ability in either group. However, 25OHD levels did correlate with working memory scores $(p=0.05)$.

One family had two control siblings and one child with PWS who had brain MRI scans as well as serum 25OHD levels. The sibling with the lowest 25OHD level (age 12; 25OHD level $27.1 \mathrm{ng} / \mathrm{mL}$ ) had the highest burden of WMH (see Figure 2a), while the sibling with an adequate 25OHD level for age (age 10; 25OHD level $29.3 \mathrm{ng} / \mathrm{mL}$ ) had $5 \mathrm{WMH}$ (see Figure 2b), and the child with PWS (age 6; 25OHD level $44.2 \mathrm{ng} / \mathrm{mL}$ ) did not have any WMH, indicating that the 25OHD levels correlate with the presence of WMH rather than with a genetic predisposition for white matter disease within the family.
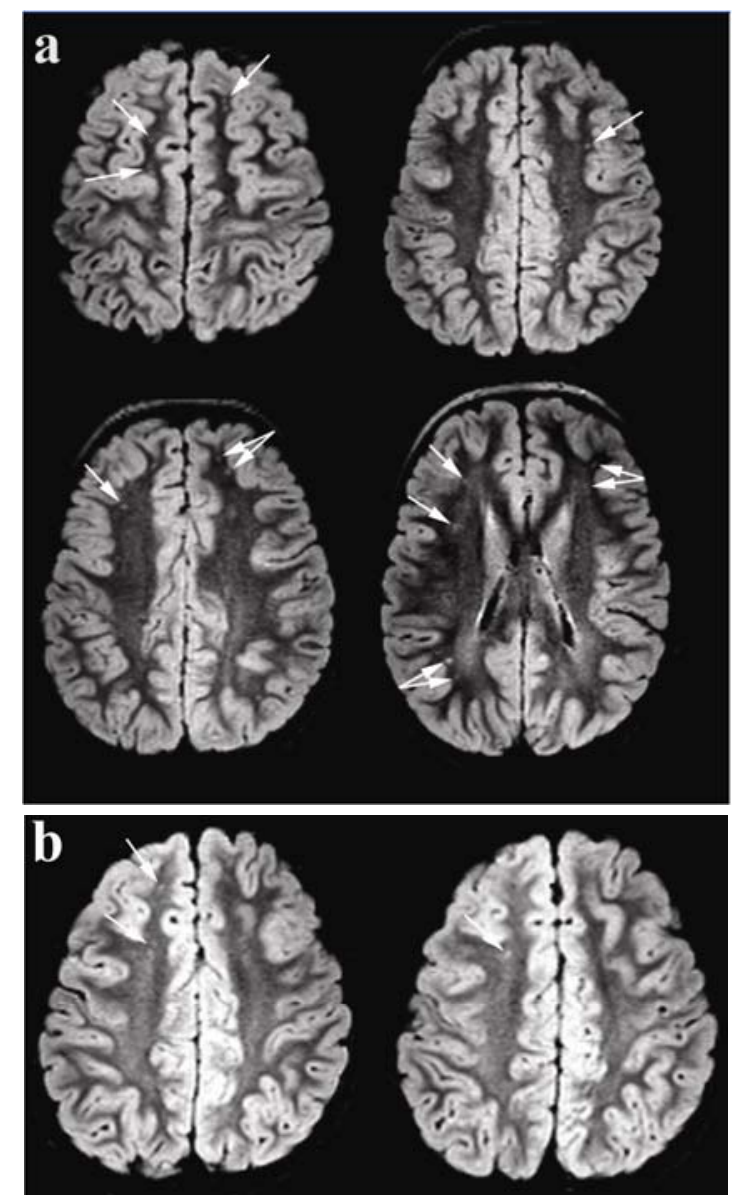

Figure 2. White matter hyperintensities and serum vitamin D levels in normal weight siblings. Axial FLAIR images of the 12 year old normal weight sibling (a) with a $25 \mathrm{OHD}$ level of $27.1 \mathrm{ng} / \mathrm{mL}$ and 28 white matter hyperintensities demonstrate multiple white matter lesions (arrows). Axial FLAIR images of the 10 year old normal weight sibling (b) with a $250 H D$ level of $29.3 \mathrm{ng} / \mathrm{mL}$ reveal decreased number of white matter lesions when compared to the 12 year old sibling. The child with PWS (not shown) had no white matter lesions with a normal 25OHD level of $44.2 \mathrm{ng} / \mathrm{mL}$.

All individuals in this study had repeat MRI scans performed two years after the initial scans and 11 of those with PWS had repeat 25OHD levels performed again at the time of the second scan. There was a significant statistical association between 25OHD levels and change in WMH between the two scans $(p=0.029)$. Those who had persistently subnormal $25 \mathrm{OHD}$ levels (less than $25 \mathrm{ng} / \mathrm{mL}$ ) had increased burden of WMH on their second scan (see Table 2; Figure 3), while those who had improvement in 25OHD levels between the two scans had stabilization, or in one case improvement, in burden of WMH on the second scan. 
Table 2. Relationship of 25OHD levels and \# WMH

\begin{tabular}{|c|c|c|c|c|c|c|c|c|}
\hline Pt \# & $\begin{array}{l}\text { Age at initial } \\
\text { MRI }\end{array}$ & $\begin{array}{l}\text { Age at } \\
\text { follow up } \\
\text { MRI }\end{array}$ & $\begin{array}{l}\text { BMI SDS at } \\
\text { initial MRI }\end{array}$ & $\begin{array}{l}\text { BMI SDS on } \\
\text { follow up MRI }\end{array}$ & $\begin{array}{l}250 H D \text { levels } \\
\text { at initial MRI }\end{array}$ & $\begin{array}{l}\text { 25OHD levels } \\
\text { on follow up } \\
\text { MRI }\end{array}$ & $\begin{array}{l}\text { \# WMH at } \\
\text { initial MRI }\end{array}$ & $\begin{array}{l}\text { \# WMH on } \\
\text { follow up } \\
\text { MRI }\end{array}$ \\
\hline 1 & 33 & 40 & 1.22 & 1.66 & 20 & 24 & 7 & 51 \\
\hline 2 & 26 & 28 & 1.11 & 1.03 & 38 & 33.1 & 0 & 14 \\
\hline 3 & 22 & 24 & 1.99 & 0.39 & 38 & 22.3 & 14 & 15 \\
\hline 4 & 24 & 30 & 0.80 & 0.84 & 64 & 34.7 & 3 & 11 \\
\hline
\end{tabular}

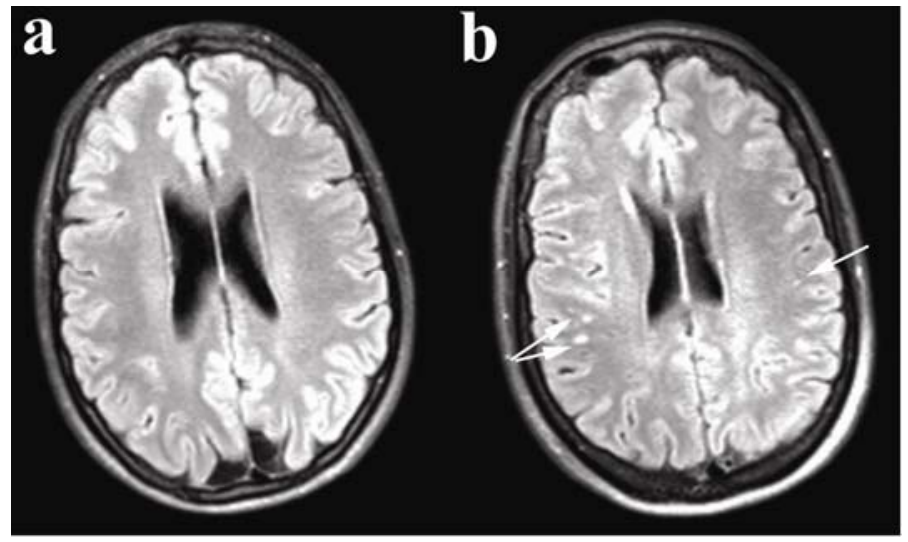

Figure 3. Progression of white matter hyperintensities with persistent low serum vitamin D levels in a patient with PWS. Initial axial FLAIR image of a 33 year old male with PWS with a 25OHD level of $20 \mathrm{ng} / \mathrm{mL}$ shows no apparent white matter hyperintensities on this slice (he had 7 lesions overall), while a follow up MRI examination (b) reveals a cluster of white matter hyperintensities in the right hemisphere and a single lesion in the left hemisphere (arrows). The patient's $25 \mathrm{OHD}$ level had remained low during the interval between scans and at the time of the follow-up scan was $24 \mathrm{ng} / \mathrm{mL}$.

\section{Discussion}

Previous MRI studies in elderly individuals (mean age 73.5) have shown an inverse relationship between serum 25OHD levels and the presence of ischemic infarcts and $\mathrm{WMH}^{[18,19]}$. In this small study we found that the presence of WMH correlated with reduced serum 25OHD levels in much younger individuals with PWS, and even in a few normal weight control siblings. The lack of statistical correlation between WMH and BMI SDS, percentage of body fat, age, gender, or GIA as well as the occurrence in normal weight control siblings supports our suspicion that the vitamin D level might play a critical role in the development of WMH. In addition, the stability of WMH in patients with normal vitamin D levels on follow up in contrast to progression in patients with persistent abnormal levels even further reinforces the significance of vitamin D as neuroprotective agent. In the individuals with PWS, 25OHD levels were correlated with overall GIA and working memory, suggesting that, in addition to increasing the risk for WMH, there may be supplementary negative effects of hypovitaminosis D on cognitive skills. Given the prevalence of low levels of vitamin D in individuals with obesity and or metabolic syndrome, our findings suggest that children with obesity may be at increased risk for WMH and even cognitive dysfunction due to hypovitaminosis D.

Vitamin D is a neurosteroid hormone which has been shown to have anti-neurodegenerative as well as anti-ischemic effects, by binding to the neuronal Vitamin D Receptors ${ }^{[20]}$. A growing body of neuropsychological research has demonstrated that hypovitaminosis D in adults is correlated with impairments in executive functions, particularly in mental shifting and information updating ${ }^{[14,21-23]}$. PWS is associated with high rates of behavior problems including temper tantrums, compulsive behavior, perseverative speech, rigid thinking, and difficulty with mental shifting ${ }^{[1,2]}$. In this small study, we found that cognitive ability in individuals with PWS was correlated with vitamin D levels, indicating that 
vitamin D status should be closely monitored in these individuals and corrected if hypovitaminosis D is identified. Additional research is needed to determine if the combination of low vitamin D levels and WMH contribute to the myriad of behavioral and learning issues in individuals with PWS.

Hypovitaminosis D may contribute to degenerative or vascular lesions that may be the cause of the WMH in individuals

with PWS ${ }^{[18,19]}$. In our previous study we noted that individuals with early-onset obesity also had WMH on brain MRI scan ${ }^{[17]}$, but unfortunately in this study, we did not have serum 25OHD levels in individuals with early-onset obesity to perform the analysis. In our larger study we also noted that those patients with WMH had lower cognitive function than normal weight sibling controls ${ }^{[17]}$. As there is a high prevalence of low vitamin D levels in children with obesity ${ }^{[24]}$, and studies in elderly patients have shown a relationship between hypovitaminosis D and decreased cognitive function ${ }^{[23]}$, this issue clearly deserves additional research in childhood obesity and PWS. PWS is an excellent model of childhood obesity, because the weight gain occurs in a predictable pattern during an expected age range (18 months-4 years). Given our findings in these individuals with PWS and the frequency of vitamin D deficiency in children with obesity, it will be of critical importance to further study brain development in individuals with childhood obesity.

The limitations of this study include the small sample size and limited number of normal weight controls. We plan to undertake larger studies to further characterize the relationship between vitamin D levels, cognitive function, obesity, and WMH in individuals with PWS, early-onset obesity, and controls.

\section{Acknowledgments}

The authors would like to thank Dr. Daniel Driscoll, Ph.D., M.D. for his mentorship and assistance in this study. Funding Support provided by: National Institutes of Health NIH 1K23 DK081203 (JLM). The content is solely the responsibility of the authors and does not necessarily represent the official views of the National Center for Research Resources or the National Institutes of Health.

\section{References}

[1] Cassidy SB, Driscoll DJ. Prader-Willi syndrome. Eur J Hum Genet. 2009 Jan; 17(1): 3-13. PMid:18781185 http://dx.doi.org/10.1038/ejhg.2008.165

[2] Butler MG, Fischer W, Kibiryeva N, et al. Array comparative genomic hybridization (aCGH) analysis in Prader-Willi syndrome. Am J Med Genet A. 2008 Apr 1; 146(7): 854-60. PMid:18266248 http://dx.doi.org/10.1002/ajmg.a.32249

[3] Bonfig W, Dokoupil K, Schmidt H. A special, strict, fat-reduced, and carbohydrate-modified diet leads to marked weight reduction even in overweight adolescents with Prader-Willi syndrome (PWS). ScientificWorldJournal. 2009 Sep 14; 9: 934-9. PMid:19768349 http://dx.doi.org/10.1100/tsw.2009.105

[4] Lindmark M, Trygg K, Giltvedt K, et al. Nutritient intake of young children with Prader-Willi syndrome. Food Nutr Res. 2010 Mar $17 ; 54$.

[5] Oliveira RM, Novaes JF, Azeredo LM, et al. Association of vitamin D insufficiency with adiposity and metabolic disorders in Brazilian adolescents. Public Health Nutr. 2013 May; 9: 1-8.

[6] Wamberg L, Kampmann U, Stødkilde-Jørgensen H, et al. Effects of vitamin D supplementation on body fat accumulation, inflammation, and metabolic risk factors in obese adults with low vitamin D levels - Results from a randomized trial. Eur J Intern Med. 2013 Apr; 5. PMid:23566943 http://dx.doi.org/10.1016/j.ejim.2013.03.005

[7] Vanlint S. Vitamin D and obesity. Nutrients. 2013 Mar 20; 5(3): 949-56. PMid:23519290 http://dx.doi.org/10.3390/nu5030949

[8] Wang C. Role of vitamin d in cardiometabolic diseases. J Diabetes Res. 2013; 2013: 243934. PMid:23671861 http://dx.doi.org/10.1155/2013/243934

[9] Gunta SS, Thadhani RI, Mak RH. The effect of vitamin D status on risk factors for cardiovascular disease. Nat Rev Nephrol. 2013 Jun; 9(6): 337-47. PMid:23609564 http://dx.doi.org/10.1038/nrneph.2013.74

[10] van Dijk EJ, Prins ND, Vermeer SE, et al. C-reactive protein and cerebral small-vessel disease: the Rotterdam Scan Study. Circulation. 2005 Aug 9; 112(6): 900-5. PMid:16061741 http://dx.doi.org/10.1161/CIRCULATIONAHA.104.506337 
[11] Annweiler C, Montero-Odasso M, Muir SW, et al. Vitamin D and Brain Imaging in the Elderly: Should we Expect Some Lesions Specifically Related to Hypovitaminosis D? Open Neuroimag J. 2012; 6: 16-8. PMid:22423308 http://dx.doi.org/10.2174/1874440001206010016

[12] van der Schaft J, Koek HL, Dijkstra E, et al. The association between vitamin D and cognition: a systematic review. Ageing Res Rev. 2013 May; 29. PMid:23727408 http://dx.doi.org/10.1016/j.arr.2013.05.004

[13] Soni M, Kos K, Lang IA, et al. Vitamin D and cognitive function. Scand J Clin Lab Invest Suppl. 2012 Apr; $243: 79-82$. PMid:22536767

[14] Slinin Y, Paudel M, Taylor BC, et al. Association between serum 25(OH) vitamin D and the risk of cognitive decline in older women. J Gerontol A Biol Sci Med Sci. 2012 Oct; 67(10): 1092-8. PMid:22454371 http://dx.doi.org/10.1093/gerona/gls075

[15] Annweiler C, Fantino B, Le Gall D, et al. Severe vitamin D deficiency is associated with advanced-stage dementia in geriatric inpatients. J Am Geriatr Soc. 2011 Jan; 59(1): 169-71. PMid:21226693 http://dx.doi.org/10.1111/j.1532-5415.2010.03166.x

[16] Kesby JP, Eyles DW, Burne TH, et al. The effects of vitamin D on brain development and adult brain function. Mol Cell Endocrinol. 2011 Dec 5; 347(1-2): 121-7. PMid:21664231 http://dx.doi.org/10.1016/j.mce.2011.05.014

[17] Miller J, Kranzler J, Liu Y, et al. Neurocognitive findings in Prader-Willi syndrome and early-onset morbid obesity. J Pediatr. 2006 Aug; 149(2): 192-8. PMid:16887432 http://dx.doi.org/10.1016/j.jpeds.2006.04.013

[18] Deluca GC, Kimball SM, Kolasinski J, et al. The Role of Vitamin D in Nervous System Health and Disease. Neuropathol Appl Neurobiol. 2013 Jan; 21. PMid:23336971 http://dx.doi.org/10.1111/nan.12020

[19] Buell JS, Dawson-Hughes B, Scott TM, et al. 25-Hydroxyvitamin D, dementia, and cerebrovascular pathology in elders receiving home services. Neurology. 2010 Jan 5; 74(1): 18-26. PMid:19940273 http://dx.doi.org/10.1212/WNL.0b013e3181beecb7

[20] Briones TL, Darwish H. Vitamin D mitigates age-related cognitive decline through the modulation of pro-inflammatory state and decrease in amyloid burden. J Neuroinflammation. 2012 Oct 25; 9: 244. PMid:23098125

http://dx.doi.org/10.1186/1742-2094-9-244

[21] Hansen AL, Dahl L, Bakke L, et al. Vitamin D and executive function: a preliminary report. Percept Mot Skills. 2011 Oct; 113(2): 677-85. PMid:22185082 http://dx.doi.org/10.2466/02.09.13.15.16.PMS.113.5.677-685

[22] Slinin Y, Paudel ML, Taylor BC, et al. 25-Hydroxyvitamin D levels and cognitive performance and decline in elderly men. Neurology. 2010 Jan 5; 74(1): 33-41. PMid:19940271 http://dx.doi.org/10.1212/WNL.0b013e3181c7197b

[23] Buell JS, Scott TM, Dawson-Hughes B, et al. Vitamin D is associated with cognitive function in elders receiving home health services. J Gerontol A Biol Sci Med Sci. 2009 Aug; 64(8): 888-95. PMid:19377013 http://dx.doi.org/10.1093/gerona/glp032

[24] Feng L, Li JR, Yang F. Relationship of serum 25-hydroxyvitamin D with obesity and inflammatory cytokines in children. Zhongguo Dang Dai Er Ke Za Zhi. 2013 Oct; 15(10): 875-9. PMid:24131841 